\title{
Theoretical framework for analysing green web applications
}

\author{
Christian Elling Scheele \\ PhD Fellow, Department of Political Science, University of Copenhagen
}

This paper evaluates the appeal of four Danish green web applications. How can the appeal of the applications be enhanced, and-more importantly-how can behavioural changes of the users be incentivised?

\section{Introduction}

In Denmark there is a broad political consensus regarding the need to address the problem of unwanted climate changes caused by increased $\mathrm{CO} 2$-emissions. It has been decided that before the year 2050 Denmark should satisfy all domestic energy demands without the use of fossil fuels (Goenergi 2011b). Thus there exists a political discourse, which has at its core recognition of the immediate need for reducing $\mathrm{CO} 2$-emissions in order to prevent long term destructive climate changes.

At the household level one consequence among others is that everybody will need to find a replacement for their oil and natural gas furnaces. Also fossil fuel transportation technology - e.g. cars and lorries that run on petrol and conventional diesel oil - will need replacement. This constitutes an epic challenge if we want to maintain our current standards of living.

On the supply side of the "carbon equation", Danish governments on both sides of the political spectrum have implemented a catalogue of initiatives with the purpose of reducing CO2-emissions, e.g., national expansion of district heating and increased use of sustainable energy sources such as windmills (Energistyrelsen 2008).

On the demand side, rising global energy prices and increased domestic taxation of fossil fuels have incentivised households to reduce their fossil energy consumption (Jyllandsposten 2009). Furthermore, the present government has developed a number of initiatives aimed specifically at reducing carbon emission (Klima og Energiministeriet 2011). For example, "The Danish Electricity Saving Trust" has developed a green web application aimed at promoting initiatives whereby buildings can be heated more efficiently (Goenergi.dk 2011b). The reason for developing the application is that half of Denmark's energy consumption is being used for this purpose. It is this type of so-called "green web application" that is the subject of this article.

The concept of a "green web application" is new within the realm of political science. Research has been conducted on climate issues within many branches of political science - international politics, public administration and comparative politics (Nedergaard 2009 \& Helm 2009). There has been a considerable amount of research on "web applications" and information and communication technology (ICT) in politics. Additionally, Danish research has focused on how one can motivate households to change to electricity-conscious behaviour (Kanstrup og Christiansen 2009, Grønhøj \& Thøgersen 2010). However, the combination of green web applications and politics raises two issues. Firstly, which methodology is beneficial when researching green ICT in a political context? The challenge is to finding an approach with heuristic value that is specific enough to shed light upon the nuances in green ICT. Secondly, an issue at stake is to examine which challenges are involved in creating a green web application appealing to mass participation across the spectrum of different human psychological, economic, and social conditions. 
Methodology - hypotheses, outline, purpose

The hypotheses below will be a guide for the structure of the analysis. On basis of the analysis each hypothesis will either be verified or falsified.

Hypothesis 1: Multiple opposed incentive mechanisms in green ICT do not cancel each other out.

Hypothesis 1 deals with the question of how a green web application should be constructed in order for it to have the widest and strongest possible appeal to prospective users. How an application appeals to us will in this analysis be related to which type of incentive potentially affects us the most. This is, e.g., opposed to a usability approach, which would focus on the ease of use of the application. Some people are motivated by economic gains, others by social gain, e.g. in the shape of a good reputation, and others again are attracted by stability in life, i.e., having to make as few life-changes as possible. These incentives may potentially be mutually opposed to one another. Especially with regard to the climate issue economic gains are often opposed to social gains.

The question raised in this paper is how far it is possible and beneficial to employ different types of incentives in a single green web application?

Hypothesis 2: Analysing green web application in the presented theoretical framework has heuristic value in that it brings forward contrasts in a comparative analysis and creates basis for developing hypotheses for future research.

Hypothesis 2 focuses on the methodological benefits of using the applied theoretical framework. It is the first time that the theoretical framework has been used in regards to analysing green ICT. It could be beneficial to investigate if the theory creates basis for better understanding the contrasts between the web applications and for developing further hypothesis for future research purposes. The reason for testing this hypothesis is thus to make a "heuristic test" of the framework theory. There is very limited - if any - theoretical material aimed at researching green ICT. Thus, future research in this area depends on the development of theories that spark new hypotheses.

\section{Outline}

After an introduction there is a methodological section containing the purpose of the paper and remarks regarding the chosen scientific method. Subsequently there will be a presentation of the theories. This will be followed by a presentation of the empirical data, which will be divided into four subsections - each presenting one web application.
The analysis will be made on the basis of the presentation of the theoretical and empirical material. In the analysis focus will be on similarities and differences in the applications in regard to how they appeal to different users. During the analysis the incentives in the applications will be discussed in the light of the neo-institutional theories. It will be shown why one application as opposed to another has more appeal to one type of human being. Thus the analysis concludes by mapping a structure of human practice matched with the web applications, where the focus is on whether the application has appeal towards the target user.

In the analysis a distinction will be made between three types of human practice - or institutions - with related incentives. These institutions spawn different types of human prototypes (or stereotypes): Firstly, there is the accountant who will change behaviour according to cost-benefit analysis aimed at generating the highest possible "rate of return". This represents the "rational choice" institution. Secondly, there is the environmentalist who is driven by a "logic of appropriateness" based on natural, rightful, and legitimate eco-friendly rules and exemplary behaviour. This represents the "normative" institution. Thirdly, there is the traditionalist whose behaviour is determined by "the way things are being or have been done", as reflected in informal rules and formal laws. This represents the historic institution (Campbell 2004).

The analysis will aim to show the relationship between the green web applications and their appeal from the perspective of the different institutionalisms. Secondly, the analysis will describe their potential effect on behavioural changes that support a political discourse based on the need of reducing $\mathrm{CO} 2$-emissions.

The figure below shows the elements in the structure and the curve shows the concept of the relationship between software, institutions and the political discourse.

The article will end with a verification or falsification of the hypotheses and a conclusion.

\section{Purpose}

The article has two purposes. Firstly, to examine the heuristic value of the chosen theoretical framework that depicts ICT in a political system. Secondly, to test the hypothesis by means of analysis of the appeal of the four green web applications.

The overlying theoretical framework shows how ICT is to be understood in a political context. However, in order to conduct the analysis, neo-institutional theory will be amalgamated with the theoretical framework in order to create an operational theoretical whole. By "an operational theoretical whole" is meant the necessity of having 


\section{ICT \\ Green Web Applications $\leftrightarrow$ Institutions/Practice $\leftrightarrow$ Sustain Discourse}

\section{Political Discourse}
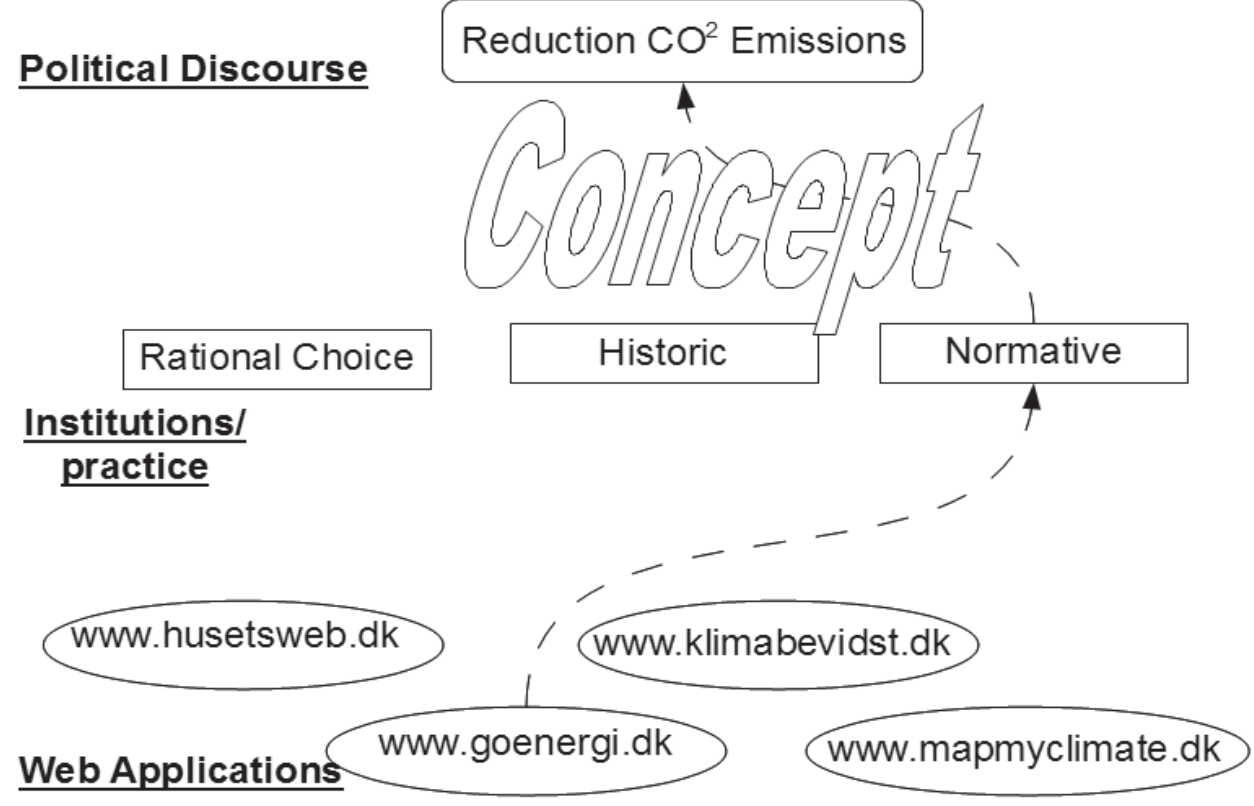

sufficient theoretical material from which one can derive a hypothesis that can be subjected to scientific testing.

The neo-institutional theory which will be applied in its three different versions is chosen because as a social theory it has explanatory power in regard to human behavioural changes. Thus the neo-institutional theory is selected because of the type of empirical data - web applications that aim at people changing their behaviour - and would not necessarily have been chosen if the empirical focus had been different.

The article operates at two theoretical levels. There is the overlying theoretical framework, which is general in regard to all ICT in political systems. The article shows how this general theoretical framework can be fused with operational neo-institutional theories. The operational theoretical material has been selected according to the empirical subject matter - the green web applications.

\section{Theory}

The theoretical basis of the article consists of a framework theory aimed at showing how ICT is to be conceived of in a political system. Furthermore three different types of the neo-institutional social theory will be introduced in order to facilitate an understanding of how different "institutions" can explain human behavioural changes. The three different versions of neo-institutional theory are "rational choice", "normative (or sociological)", and "historic" institutionalism that each in their own way have a preferred notion of causal relationships and views on the role of ideas.

\section{Theoretical framework - ICT}

The theoretical framework shows how Information and Communication Technology (ICT) can be understood as four different elements in dialectic interaction in a political system. The elements are (political) discourse, practice, software and hardware. A "discourse" is a discursive hegemony which in this context is a stable political discourse (Foucault 1969; Laclau Mouffe 1985).

"Social practice" is a combination of the individual's continuously reproduced actions, beliefs and deliberations (Giddens 1979, 1984). Practice can thus both be unexpected, novel, and even revolutionary, however, it can also be - and maybe more often - uninspiring, re- 


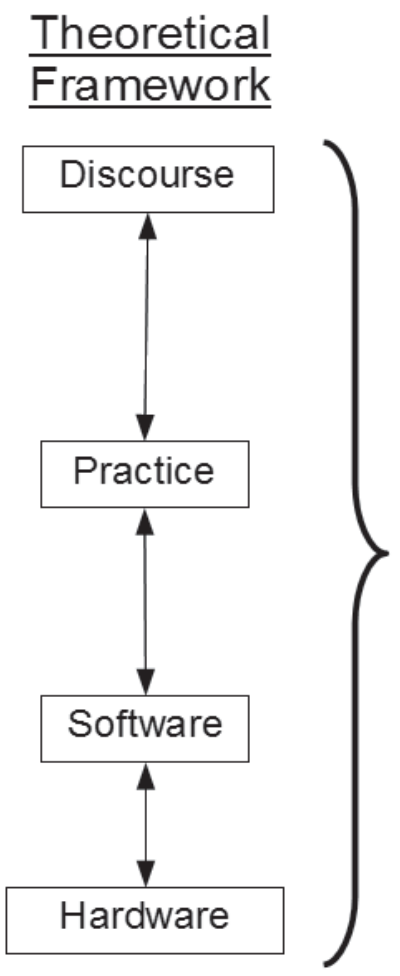

\section{Empirical Basis \& Subject Matter Dependent Theories}

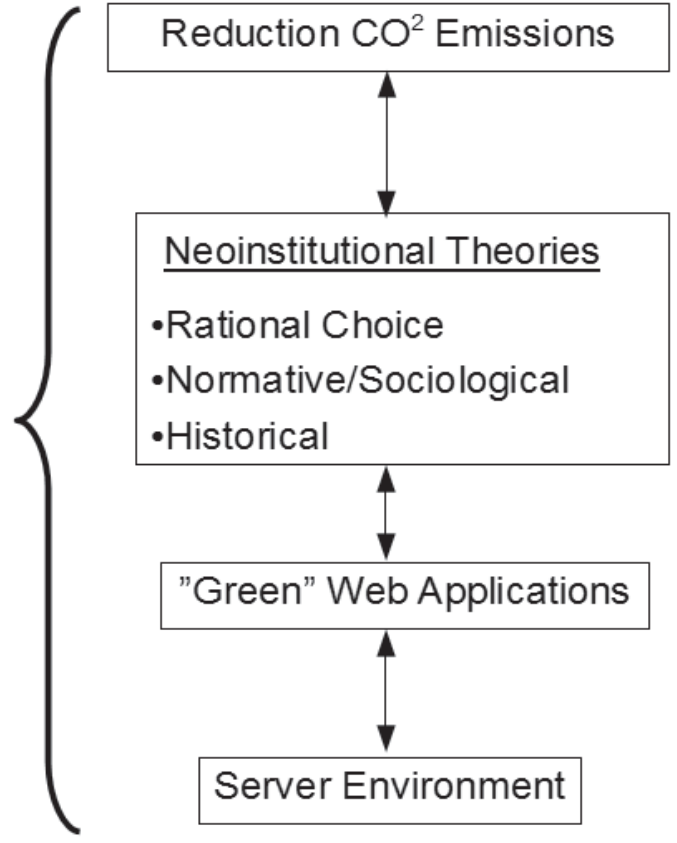

petitive, and routine-based. According to Giddens, institutions are merely an expression of regularised practice (Hoff 2004). Practice can thus be said to express the view from within a superior institution regarding how "things should get done" or what behaviour is expected of the individual (March \& Olsen 1984).

Computer software is a combination of coded programs, algorithms, documentation and data, which require hardware to function. Hardware is the physical artefact consisting of all the tangible elements in a computer.

According to the framework theory in Figure 2, the four elements described above are linked to each other by double-sided arrows. The arrow pointing up signals "presupposes" which should be understood in such a way that software presupposes hardware and practice presupposes software. A (political) discourse is presupposed by practice (Hoff 2004). However, the arrow pointing up also has the meaning "creates the basis for" in such a way that hardware creates the basis for software, software creates the basis for practice, and practice creates the basis for discourse. The arrow pointing down signals "affects", meaning that discourse affects practice which again affects software that lastly affects hardware.

\section{Theoretical framework - ICT: deployed}

The right side of Figure 2 depicts the empirical basis and the theory which is then "inserted" into the framework theory depending upon the subject matter of the empirical data. The elements on the left side vis-a-vis the right side in Figure 2 are shown parallel to each other. The top right hand corner shows the political discourse, which in this case revolves around the immediate need for addressing the problem - the need to reduce our CO2-emissions in order to mitigate unwanted climate changes. There are different sources for CO2-emission, however, the most important one is associated with our consumption of fossil fuels e.g. natural gas or oil for furnaces and petrol or diesel oil used for transportation in cars, buses and lorries. CO2 emissions from burning fossil fuels have increased at an average annual rate of $3.4 \%$ between 2000 and 2008, compared with one per cent per year in the 1990s (ScienceDaily 2009a). Using a combination of global climate models and historical climate data it has 
Table 1: Presentation of the Three Institutionalisms

\begin{tabular}{|l|l|l|l|}
\hline & Rational Choice & Normative/Sociological & Historical \\
\hline $\begin{array}{l}\text { Institutional } \\
\text { definition }\end{array}$ & $\begin{array}{l}\text { Institutions are laws, informal rules and comp- } \\
\text { liance procedures which push society towards } \\
\text { strategic equilibrium }\end{array}$ & $\begin{array}{l}\text { Institutions are rules, social frameworks that are ta- } \\
\text { ken for granted, cognitive schemas, and processes } \\
\text { reproducing the above-mentioned elements }\end{array}$ & $\begin{array}{l}\text { Formal and informal rules and } \\
\text { procedures }\end{array}$ \\
\hline Role of ideas & $\begin{array}{l}\text { Cognitive structures, beliefs, and norms con- } \\
\text { strain the actor }\end{array}$ & $\begin{array}{l}\text { Normative and cognitive structures which are taken } \\
\text { for granted restrain and enable the actor }\end{array}$ & $\begin{array}{l}\text { Policy paradigms and stable wide- } \\
\text { spread beliefs constrain the actor }\end{array}$ \\
\hline $\begin{array}{l}\text { Concepts of } \\
\text { causality }\end{array}$ & $\begin{array}{l}\text { Path dependence based on search for } \\
\text { increasing returns based on cost-benefit } \\
\text { analysis within the framework of institutions, } \\
\text { which constrain the actor }\end{array}$ & $\begin{array}{l}\text { Path dependence based on constraining and em- } \\
\text { powering institutions }\end{array}$ & $\begin{array}{l}\text { Path dependence based on } \\
\text { learning over time, feedback, and } \\
\text { choice within the framework of in- } \\
\text { stitutions, which constrain the actor }\end{array}$ \\
\hline
\end{tabular}

Note: based on Campbell 2004.

been shown that there is a simple linear relationship between total cumulative emissions and global temperature change (ScienceDaily 2009b). This strongly suggests that it is increased CO2-emissions that have caused the global temperature to rise.

\section{Framework theory - ICT:}

\section{neo-institutionalism as practice}

Practice is conceived of in terms of institutions. Three different versions of institutions are applied in order to explain the expected relationship between the green web applications and behaviour change. The table gives the reader a quick comparative overview of the three institutional theories(Campbell 2004).

The empirical basis is practice with a focus on behavioural change that presupposes software - or software creates the basis for practice. The software consists in the four green web applications. Their similarities are their subject matter - reduction of $\mathrm{CO} 2$-emissions - and the fact that they all operate within an Internet browser.

There are minor technical differences between the four applications. Some of them require an extra "plugin" in order to render complex dynamic elements such as interactive environmental graphic simulations. The plugins are free of charge and can be automatically downloaded and installed on the hardware when the user tries to execute the application for the first time. In regard to hardware the applications presuppose a server environment. The user also needs a piece of hardware at the receiving end, which in principle could be anything from a PC to a smart phone.

The theoretical material will be used in the analysis of the appeal of the green web applications which follows below.

\section{Empirical Data}

The empirical data is four selected Danish web applications that in each their way incentivises behavioural change towards reducing the consumption of fossil fuel. This section will describe the selection criteria that have been applied in order to select the most relevant green web applications. That will be followed by a description of each web application. The description is aimed at showing important differences (and similarities).

\section{Data Selection}

The four green web applications have been chosen on the basis of the following selection criteria:

1) The application must be in a language spoken in only one country. Danish has been chosen. By choosing a language spoken only in one country the idea is to reduce the effect that different macro-societal parameters such as law, tradition and history can otherwise have on practice. E.g. since applications in English could be relevant in several countries that have English as their primary language it was not chosen.

2) Applications must motivate behavioural changes. The focus of the article is on voluntary human behavioural change as a source of reducing $\mathrm{CO} 2$-emissions rather than e.g. behaviour changes that are derived from changed legislation.

3) Applications that have a potential for being biased are avoided. Thus applications developed by companies that sell products related to e.g. energy consumption have been avoided.

4) The application must be free of charge for the user. If a person is prepared to pay for the use of an application then it could be argued that the user is biased towards a behaviour change - especially because it can be expensive (almost EURO 600) to use such an application. In other words, it is likely that a user only pays for the use of an application if the user has decided in advance that he/she wants to make a change.

The web applications that satisfied all selection criteria were four at the time of writing (middle of 2011): https:// 
www.husetsweb.dk. https://www.goenergi.dk/forbruger/ boligtjek, www.klimabevidst.dk and http://mapmyclimate.dk/

In the following section each web application will be described according to the key parameters:

Target Group - who is the target audience

Key Concept - what are the core functionalities in the applications

Data Output - which data is being generated and how is it composed

\section{Husetsweb.dk}

Husetsweb.dk is an application aimed at people owning their own house and who are prepared to invest in initiatives aimed at reducing costs related to fossil energy consumption. The application has been developed by a private company. The company then sells the application to local governments who pay for letting their citizens use it free of charge. However, in reality all citizens have access to the application even though they might not reside in the area of one of the local governments that have paid the fee. This is not a accidental but a conscious strategic decision made by the developing company.

\section{Target Group}

The primary target group is the existing housing stock limited to small houses, which are defined as houses smaller than 1000 square meters. This category also includes detached houses, villas, town houses and farmhouses. Thus the gross target group consists of approx. 700.000 private dwellings. The target audience are users who would not on their own initiative initiate an energyoptimising project - otherwise they would probably not benefit from using the application.

\section{Key Concept}

The application functions as a form of "virtual energy consultant" that produces recommendations about changes that can be made to the physical construction of the house making it more energy efficient.

The application requires the owner of the house to load a series of items of information into the application regarding issues that are relevant to the energy consumption in the house. The owner loads the application with data regarding the size of the energy bill, number of people living in the house, and number of windows and doors.

The user also writes the address of the house in the application form. This is used by the application to automatically gather data from different official data bases that contain relevant information about the house, such as its age, size of the house, and, e.g., whether or not the house is placed in a zone with district heating.

The data is processed and the user receives a digital "energy action plan" with a related "finance budget". The key concept is thus to supply the user with a list of financially sustainable suggestions regarding possible physical changes that can be made on the house, which would make it more energy efficient. There are three principles in the financial model. Firstly, all initiatives should be financed by the amount of money saved from a future lower energy bill. Secondly, the initiative must be fully paid by savings on the energy bill within no more than 15 years. Thirdly, the capital gain that the initiative might give to the house is not taken into consideration. Thus there is relatively narrow definition of which initiatives are viable: The owner must receive a financial gain or at least not a loss when implementing one or more of the recommendations in the output report.

The focus is primarily on physical changes that can be made to a house. The potential behaviour change is aimed at how the owner of the house maintains and develops his or her property on a long term basis. Thus there is hardly any focus on short term behavioural changes such as lowering the house temperature, choosing the shower rather than a bath, or persistently buying more energy efficient household products.

\section{Data Output}

The key output of the application is the "energy action plan" containing a list of initiatives that the house owner can implement him- or herself or hire a craftsman for the job. The calculations are made on the presumption that a professional will do the job. If the owner chooses not to engage a professional then the financial benefit could be larger.

Here is a list of three examples of initiatives generated by the application starting with the low cost and ending with a high cost. A relatively low cost initiative could be insulating pipes that transport hot water thus avoiding loss of energy when water is transported from the boiler to the water taps. A more expensive initiative could be changing the outer doors to new energy efficient doors that prevent draughts and insulate better. An expensive initiative with a long write-off period could be installation of a new central heating system that can partly function using sustainable energy, e.g., geothermal energy.

The application also generates a "finance budget" with information on the costs of each initiative based on having a professional craftsman doing the job. The "finance budget" includes information regarding the costs of materials, costs related to the amount of working hours, and financial costs, e.g., interest rates on a loan 
needed to finance the suggested initiatives. The gross yield of the loan is determined on assumptions about the type of loan or mortgage, transaction costs and fixed or variable interest rates.

\section{Goenergi.dk}

Goenergi.dk/forbruger/boligtjek is an application analogous to Husetsweb.dk, however, it is more advanced and more user-friendly due to its simple graphic interface. The application is also applicable to people in rented houses, flats, or permanently living in a vacation house. The application is fully financed by the state.

\section{Target Group}

The target audience is private households, government and industry. The focus is on their use of energy in all areas except transport. The target audience is thus very broad, which is also reflected in the relatively high number of applications that are on the website. The primary application is "boligtjek" or "house check" and then there are a number of "sub applications" that will also be briefly mentioned as they are important in understanding the application as a whole.

\section{Key Concept}

The key concept is advice regarding how to reduce energy consumption. The user inputs a series of data to the application. This data is then used to gather data from external official databases, and is processed together with the users' data in a series of algorithms producing both online and off line output.

The application makes use of three-dimensional interactive graphics and is accessible to everybody who is able to use the Internet. This application is capable of performing the same processing and potentially supplying the same advice as Husetsweb.dk. Due to the similarity between the two applications the core processing will not be described any further.

However the scope of the application is wider than that of Husetsweb.dk, which only focuses on physical changes. This application also includes pure behavioural changes, e.g., remembering to turn off the light in room that is not in use. Such an advice is relatively unproblematic because it does not leave the user worse off than before. However, the application also suggests behavioural changes that effectively reduce comfort levels, e.g., suggesting that the room temperature is lowered. When confronted with such an advice, the user must - ad extremum - balance long term climate sustainability together with energy costs on one side against short term personal comfort on the other. One could argue that the user might achieve a psychological gain by lowering the room temperature and so being an active environmentalist.

Together with the application there is a subset of applications which each in their own way use different methods to incentivise behavioural changes. For instance, some would take the form of games. It is also possible to become an "energy family", where your family would be asked to participate in local debates regarding energy consumptions either in the printed press, digital media, or by attending local venues. One of the sub-applications has also facilitated a competition where the goal was to be the family with lowest electricity consumption viewed over a period of six months. The point here is that these sub-application could be argued to give a social or psychological benefit rather than a merely economic one.

\section{Data Output}

As mentioned above, the output is similar to that of Husetsweb.dk. The major difference is that this application has an emphasis on graphics rather than text. As an example, the on-line output has advanced threedimensional interactive drawings of the house. There is, compared to Husetsweb.dk, a much stronger focus on "benchmarking" the user measured against the "average consumer". Goenergi.dk also uses graphics when "benchmarking" the user. For example, if users have a high energy consumption, this will be illustrated by highlighting the icon of a little house which is placed close to the "red end" on a scale from green to red. The message is: "Nine out of ten users have a lower energy consumption! You use too much energy!"

The application also contains an on-line form which is formatted for reporting data from utility meters over time - e.g. the electric or natural gas meters. The form is also part of the output as it displays the development in consumption over time. The incentive behind filling out such a form can be argued to be financial as the curve on the graph depicts the consumption, which is directly linked to the utility bill. However, the tool might also be argued to have a norm-forming effect if used in a certain way. That is because such a graph would be very useful, e.g., in explaining to other members in the household about an unwanted development in energy consumption warranting behavioural change.

\section{Klimabevidst.dk}

Klimabevidst.dk is an application aimed at making companies reduce their energy consumption. The application is a catalogue of "saving guides" that the company can use as a recipe for energy reduction within a specific area, e.g. lighting, use of ICT, or transportation. The ap- 
plication is run by a company which is partly public and partly private.

\section{Target Group}

The primary target group is small and medium sized privately owned enterprises. The application can, however, equally well be used by small to medium sized public entities.

\section{Key Concept}

The key concept in this application is to promote behavioural changes in enterprises using two different methods.

The first method is based on informing the enterprise about the potential savings that could be achieved by making the necessary changes. The potential savings are estimates, and are by no means precise enough to be material for budgetary processes. Instead they are at best indicators of whether the potential is small, medium or large. The economic indicators are followed by instructions on how to achieve the savings.

The second method has to do with the way the company would like to be perceived - both internally and externally. Enterprises that use the application will be issued a "Climate Certificate" that they can use to label themselves as a climate-friendly company.

At the core of the application is an online catalogue containing approximately 200 operational guides on how the company can reduce costs by implementing environmental initiatives. These guides are sorted into 12 categories e.g. lighting, ICT, and transportation. Each category contains several more specific operational guides, e.g. a guide on sending invoices electronically rather than by mail; installation of "intelligent" light switches; or changing the glass in windows into energy efficient glazing.

The key idea in the application is to develop energy guides that can be implemented without special competences. Most small and medium sized enterprises cannot afford to set up a specific unit that has environmental projects as its sole purpose. Thus the energy guides can in reality be implemented by almost any available resource in the enterprise, e.g., a secretary, an apprentice or ITstaff. The employee(s) put in charge of implementing the energy guides is nominated as "climate responsible".

\section{Data Output}

The key output is an on-line certificate that the enterprise can use as part of their corporate branding. The certificate is a one page document with the name, address, and logo of the enterprise. The certificate shows which energy guides the enterprise has implemented. Each energy guide is scored from 1 to 10 depending on the positive impact that implementing the guide will have on the climate. When implementing the energy guides the application will sum the points from each implemented guide. The higher the score the more the enterprise can be argued to be environmentally friendly. The numeric score is, however, not displayed on the certificate but only available to the employee who is "climate responsible". Thus the achieved score will probably only have effect if the climate responsible officer communicates it to the rest of the employees and/or to the outside world.

\section{Mapmyclimate.dk}

This application is an advanced climate simulator which shows the future consequences of the users' behaviour. It also contains an interactive "CO2 diet" for people who want to reduce their $\mathrm{CO}$-emissions in order to mitigate unwanted climate changes. The application has been developed by private companies but was funded by public assets.

\section{Target Group}

The application's target audience is families with children and people living in Greater Copenhagen. The reason for the geographical limitation is that the simulations only covers Greater Copenhagen. Thus, if the user lives in the are a the user can find his or her address by zooming in on the satellite image. People who live outside of the area can still access the application and investigate the connection between energy consumption and the future climate.

\section{Key Concept}

The application contains several elements. At the core is a climate simulation that on the basis of very advanced algorithms is able to show how the climate will be in year 2100. The algorithm functions on the basis of the user reporting his or her behaviour within the climate area. This includes many different aspects of the user's everyday life that affects the climate, e.g. the temperature in the home, use of car, and the consumption of food. After answering these questions the algorithm produces a $\mathrm{CO} 2$-profile. The user's CO2-profile is then aggregated, and the simulator shows what the consequence of the user's behaviour will be on the climate in year 2100 if everybody behaved in the same way as the user. The result of the user's behaviour might be that the area that the person lives in gets flooded. If this result motivates the user to consider making changes in his or her life, the application produces a "CO2-diet". There are two versions of the "CO2-diet" - "easy advice" or "radical advice". The "easy advice" covers initiatives that the user can implement straight away, e.g. turning off the light when not being in the room, 
eating less meat and more locally produced vegetables, or considering not using the car once in a while. The "radical advice" would require change of lifestyle and/ or substantial investment, e.g. changing all windows and doors into energy efficient types, permanently giving up the use of a car, or stopping flying altogether.

\section{Data Output}

The primary output is a simulated climate map of Greater Copenhagen. As an example, a simulation was generated on the basis of a profile of an average Danish father with three children who works at a national university. The resulting map shows how the user's behaviour results in water temperature increasing in year 2100 causing death of fish and growth of unwanted algae. Maybe the message to this particular user is that he might need to follow some of the "radical advice" in the "CO2-diet" if he wants a future that would be habitable for his great grandchildren when they grow old in year 2100 . Thus this application could be argued to focus on normative incentives rather than economic ones.

\section{Comparing Incentives}

This section contains a comparative analysis where each web application will be viewed through the lens of Figure 1. Firstly, however, it will be shown how the web applications are developed on the basis of the one or more institutional understandings of causal concepts, the role of ideas, and of the very definition of institutions themselves as described in Table 1. Secondly, this will be used as a foundation for "mapping" the connection from web applications to the political discourse via the three different institutional understandings. This will lead to a discussion and conclusion about the role of multiple institutions in individual green web applications, thereby creating a basis for testing the hypothesis. The result from the comparative analysis have been structured in the table below. The reason for presenting the results "up front" is to provide the reader with a structured overview before delving into the more elaborate analysis below.

Husetsweb.dk is a green web application that revolves around economic incentives. The focus of the web application is physical changes to the user's house that will lead to decreased CO2-emissions and hence decreased expenditure on fossil energy. The application has two basic criteria for selecting the initiatives in the output to the user. The initiative should generate an economic benefit (or at least not a loss) and the comfort levels should be maintained constant. Husetsweb.dk thus creates the basis for rational choice institutionalism with its focus on increased returns as a causal mechanism promoting behavioural change. In sum, the application is based on the economic incentive to implement energy efficient initiatives. This creates the basis for a perpetuation of the political discourse: "Reduction CO2 emissions".

Goenergi.dk is in this respect similar to Husetsweb. $\mathrm{dk}$. The application is an interactive energy calculator that supplies the user with two types of advice. The first type replicates those of Husetsweb.dk - suggestions for physical changes of the owner's house (flat, or vacation house thus having a broad scope of possible users) that reduces the energy consumption. The second type are suggestions of pure behavioural changes, that will reduce the use of energy, e.g. turning down the thermostats on the radiators. Both types of advice revolve around an economic incentive. The application could thus be argued to create the basis for rational choice institutionalism. However, there are some differences.

The primary application Boligtjek uses ranking or "benchmarking" as a tool, as depicted in Figure 3 with the user being in the "red area". That signals that the user is not where the user is supposed to be - clearly a

Table 2: Overview of Central Points From the Comparative Analysis

\begin{tabular}{|c|c|c|c|c|}
\hline & Key concept & Behavioural aim & Incentives & Institutional "match" \\
\hline Husetsweb.dk & $\begin{array}{l}\text { Application aimed at energy- } \\
\text { optimising private houses }\end{array}$ & $\begin{array}{l}\text { Physical adaptations of the user's house } \\
\text { in order to reduce energy consumption }\end{array}$ & - Solely economic & $\begin{array}{l}\text { Rational choice institutio- } \\
\text { nalism }\end{array}$ \\
\hline Goenergi.dk & $\begin{array}{l}\text { On-line 3D climate friendly } \\
\text { home refurbishing guide and } \\
\text { behaviour change guide }\end{array}$ & $\begin{array}{l}\text { Physical adaptations of the user's flat, } \\
\text { house or vacation residence in order to } \\
\text { reduce energy consumption and a minor } \\
\text { element of changing habits in regards to } \\
\text { energy consumption }\end{array}$ & $\begin{array}{l}\text { - Primarily economic } \\
\text { - Minor normative } \\
\quad \text { incentives }\end{array}$ & $\begin{array}{l}\text { Rational choice institutio- } \\
\text { nalism }\end{array}$ \\
\hline Klimabevidst.dk & $\begin{array}{l}\text { Catalogue of energy saving } \\
\text { guides aimed at SMV's }\end{array}$ & Carry out energy reduction "recipies" & - Solely economic & $\begin{array}{l}\text { Rational choice institutio- } \\
\text { nalism }\end{array}$ \\
\hline Mapmyclimate.dk & $\begin{array}{l}\text { Climate simulator covering } \\
\text { Copenhagen }\end{array}$ & Go on a "radical" or "easy" CO2-diet & $\begin{array}{l}\text { - Solely normative } \\
\text { incentive }\end{array}$ & Normative institutionalism \\
\hline
\end{tabular}


normative incentive. The application also contains three sub-applications - games, the possibility of becoming an "energy family", and a six months "energy competition", which all have strong normative elements in them. Overall the application can be argued to create the basis simultaneously for normative and rational choice institutionalism.

Klimabevidst.dk revolves around the possible economic gains that can be made by changing behaviour in a more climate-friendly direction thereby reducing $\mathrm{CO} 2-$ emissions. The on-line climate certificate that the application generates when an enterprise implements the energy saving guides could in some cases be viewed as norm-setting, i.e. the company labelling itself as environmentally friendly both internally towards its employees as well as externally towards the market. However, it could equally be argued that the on-line certificate primarily serves as a marketing tool thus creating the basis for practice that supports the principle of "increased rates of return". This application is primarily seen to create the basis for rational choice institutionalism.

Mapmyclimate.dk is centred on a simulation of the climate in and around Greater Copenhagen in year 2100.
The user loads information, "energy consumption data", into the application by answering a survey. The consumption is measured against different parameters that affect the climate such as domestic heating, electricity consumption, eating habits, and use of a car. The application uses this information in its simulations of the future climate, i.e., air temperature, water temperature, and air pollution, to mention some climate features. The simulation is based on the concept of how the climate will be in 2100 if everybody has the same consumption as the user. This principle matches Kant's concept of the Categorical Imperative which states that a person acts morally if the maxim or rule of conduct on which he acts could be willed as a universal law that would govern all people in similar circumstances (Kant 1785). The application has an unequivocal focus on "moral behaviour" and thus echoes "normative institutionalism".

Summing up, each web application fits one or more neo institutional understandings, as described in Figure 5 below. In the above analysis focus has been on how the green web applications create the basis for practice and how this practice creates the basis for the political discourse. Therefore the arrows in Figure 5 only point

Figure 3: Analysis Results Illustrated

ICT

Green Applications $\leftrightarrow$ Institutions/Practice $\leftrightarrow$ Sustaining Pol. Discourse

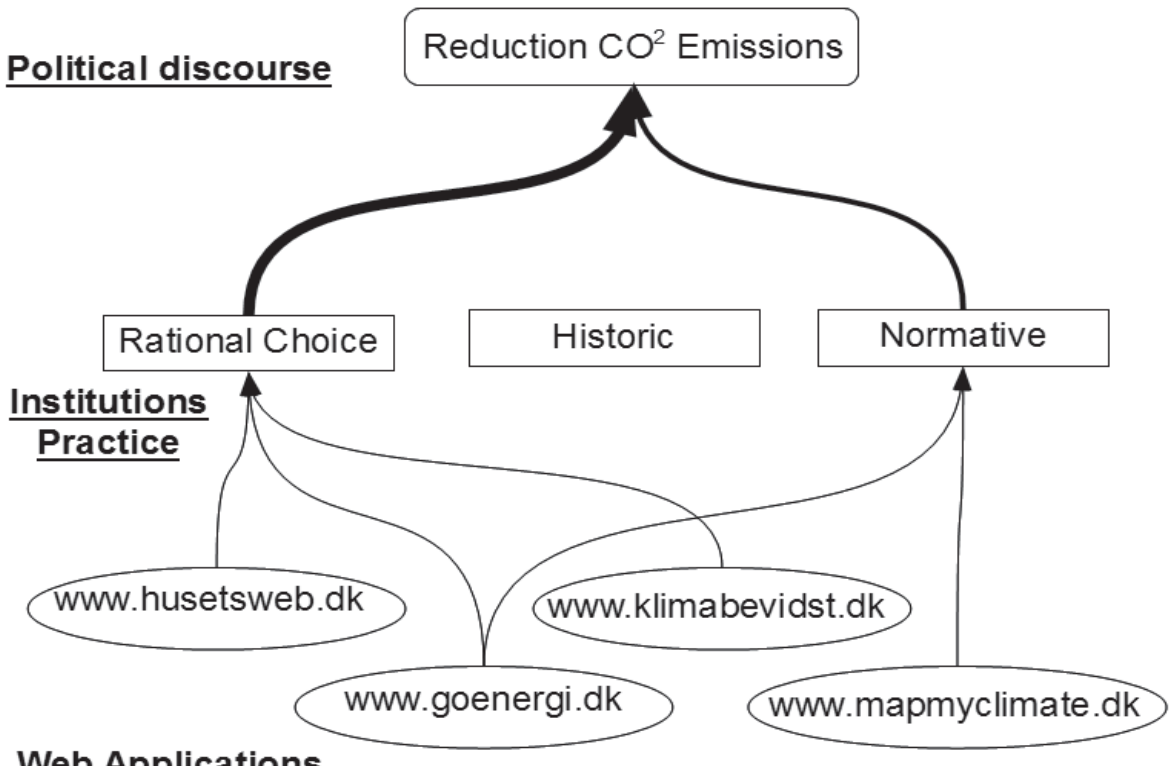

Web Applications 
in one direction. The thickness of the arrows from the institutional level to the discursive level is determined by how many arrows flow to the institutional level from the application level. Thus the arrow from "rational choice" to the discursive level is thickest because three applications create the basis for that practice or institution.

\section{Path dependency as "driver"}

When looking at Figure 3 it is striking that no web application creates the basis for "historic institutionalism" as practice - and because of this there is no arrow from "historic institutionalism" to the discursive level. On this basis one might conclude, that "historic institutionalism" plays only a marginal role compared to the other two institutions - if any at all.

In historic institutionalism the favoured causal principle is path-dependency based on "learning" or the notion "that history matters" (Campbell 2004). Well established patterns of behaviour tend to be followed through time. Understood in such a way "historic institutionalism" in this context could be argued to constitute some of the "resistance" that the applications meet when they try to make people change behaviour. The reason is that people are prone to behave as they have always done. For this reason one might conclude that green web applications should try to avoid historic institutionalism altogether.

One could, however, also argue the opposite, which might be more productive: If deployed correctly "historic institutionalism" could function as a form for "catalyst" for change. The idea would be to set up an application that functions in continuation with the user's existing behaviour.

A hypothetical example could be recycling of waste. In the U.K. recycling of waste has occurred for centuries. In the beginning the concept was one of taking valuable items out of the garbage and re-using them, but during the last two decades the agenda has increasingly been focused on the climatic benefits created by recycling (WasteOnline 2004). Everybody in the U.K. has now learned about recycling and would to a lesser or stronger - but on average increasing (Wrap 2006) - degree recycle household waste. "Recycling" could even be argued to constitute a policy paradigm.

A green web application that focuses on increased recycling would thus according to a "historic institutionalist" not need to make people do the "opposite of what they are used to" but rather encourage them to do "more, of what they are used to". There would, however, also be difficulties or limitations related to this use of "historic institutionalism". The particular example with recycling would not be applicable against those users who never recycle or those who for some reason are opposed to re- cycling. Secondly, one could also argue that "doing more of what you are use to" also constitutes a behavioural change. There again, as a counter argument one could state that "doing more of what you are use to" only constitutes a minor behavioural change compared to "doing the opposite of what you are use to".

To sum, we have all to some extend learned how to behave environmentally friendly. There are numerous different examples of how this behaviour has been institutionalised in our every day behaviour e.g. the above example regarding waste recycling in the U.K. In the United States recycling batteries have reached record breaking levels with a yearly increase of $10,1 \%$ from 2009 to 2010 (Call2Recycle 2011). We have been using energy saving compact fluorescent lamp bulbs for more than two decades (Lamptech 2012). Since the enegry crisis following the oil embargo in the 1973 there has been an ever increasing focused on insulating houses and alternative ways of heating homes (Gram, Jens Erik 2008, Adams 1987, Govan, Greason \& McAllistor 1983, Kachadorian 1997). The point is that climate friendly behaviour is already to a certain extent institutionalised on a Danish and international level as the examples above demonstrates. This creates a foundation of path dependency concerning incentivising environmentally friendly behaviour that the web applications could have benefited from. There does not seem to be a clear reason why the applications have not included the principles of path dependency as it is known from historic institutionalism.

\section{Conclusion}

\section{Hypothesis 1:}

Multiple opposed incentive mechanisms in green ICT do not cancel each other out.

On the basis of the above the hypothesis is verified.

Figure 7 shows that there is a pattern from the applications to the discourse that is bridged by the incentives mechanism - or institutional mechanics. On the basis of the analysis above the theoretical model appears to be applicable for the subject matter of the analysis, i.e. the green web applications.

People can be divided into the groups that the institutions constitute - or each of us could be said to have a blend of the institutional mechanics in us individually. A web application that supports all three institutions would thus c.p. have a higher appeal than one that only supports one or two.

From an empirical point of view there do not seem to be reasons why green web applications could not employ several incentive mechanisms at the same time. On the contrary Goenergi.dk employs principles from both a ra- 
tional choice and a normative institutional approach. The application could also have included at elements from a "historic institutionalist" approach vis-a-vis the "recycling example".

There are, however, also limitations associated with a green web application that employs all three institutional dynamics. Firstly, there are limitations to the scope of the three institutions. There might be people who do not "fit" any of the three institutions e.g. a feminist institutionalist.

Secondly, there is the issue of having opposing incentive structures employed at the same time. In employing multiple institutional mechanisms in one application it should be made sure that the application is not logically inconsistent. This might be achieved by having different sections for each incentive dynamic in the application, e.g. avoiding suggesting that the user switches to a carbon neutral life style if the headline of the section is based on continuing or slightly increasing an existing pattern of behaviour.

The third issue has to do with the gap between appeal on one side and effect on the other. This analysis partly presumes that there is linear relationship between appeal and effect, which might not be the case. Conducting a positivistic analysis of how big an impact an application has on the overall climate might also be methodologically difficult or even impossible. That is partly due to the number of parameters involved and because it is not possible to have an "independent control climate" that one could compare with. An alternative might be carrying out a survey aimed at the users of the application or analysing the flow of users over time in the applications.

\section{Hypothesis 2:}

Analysing green web application in the presented theoretical framework has heuristic value in that it brings forward contrasts in a comparative analysis and creates basis for developing hypothesis for future research.

On the basis of the above the hypothesis is verified. Using the framework has made it possible to examine green ICT in a political scientific context thus linking the applications to behaviour and from there to a political discourse.

In the comparative analysis the theoretical framework illuminated the contrasts between each application, thus making it possible to test the first hypothesis. It was particularly important firstly, to establish the "vertical" integration from ICT via practice to discourse in order to understand how ICT effectively supports or blocks the political discourse. Secondly, by inserting the institutional theory it was possible to create a "horizontal" axis at the practice level on which the comparative analysis could be carried through. Using this framework it was clear to see the different incentives mechanisms in the applications. Thirdly, in connection with testing hypothesis 1 new hypothesis was created i.e."There is a linear relationship between appeal and effect in green ICT". This hypothesis could be used as a basis for future research aimed at examining how the applications in reality appeal to the target audience i.e. whether or not the applications make them change behaviour. In extension of this it could be relevant conduct research that aims at uncovering the effects on the climate that the applications have, i.e. to which extent the applications reduces $\mathrm{CO} 2$-emissions.

The benefit of using the theoretical framework presented is its "robustness" on one side and its flexibility on the other. "Robust" signals that the theory has the potential for not only being applied to many different types of software and equally numerous different variables. This paper focused on "incentives" as a variable, which motivated an insertion of institutional theory in the framework. The theory could also be applied in an analysis aimed at usability, innovation or even compliance - thus expanding framework "horizontally" at the "practice" level of the framework.

Had focus been on other aspects, e.g. the political level it would have been equally possible to expand the "vertical" dimension of the framework with relevant parameters and analytical theories. Thus the framework functions as a form for theoretical accordion that one that contract or expand both "horizontally" and "vertically" according to the empirical subject matter.

\section{References}

Adams, JS 1987, Housing America in the 1980s, The Russel Sage Foundation, New York

Call2Recycle 2011, Record breaking increase for battery recycling in 2010. Obtained through the Internet: http://earth911.com/ news/2011/01/19/report-record-breaking-increase-for-battery-recycling-in-2010/ [accessed 21/5/2012]

Campbell, JL 2004, Institutional Change and Globalization, Princeton: Princeton University Press

Energistyrelsen 2011, Politiske Energiaftaler. Obtained through the Internet: http://www.ens.dk/da-DK/Politik/Dansk-klima-ogenergi-politik/politiskeaftaler/Sider/politiske-aftaler.aspx, [accessed 15/7/2011]

Energistyrelsen 1992, Aftale om decentral kraftvarme og vindmoller. Obtained through the Internet: http://www.ens.dk/da-DK/Politik/Dansk-klima-og-energi-politik/politiskeaftaler/Sider/Marts1992Vindmoellerogdecentralkraftvarme.aspx , [accessed 15/7/2011] Foucault, M 1969, L'Archeologie du Savoir, Gallimard.

Giddens, A 1979, Central Problems in Social Theory, Berkeley: University of California Press

Giddens, A 1984, The Constitution of Society, Cambridge: Polity Press Goenergi.dk 2011a, Handlingsplan. Obtained through the Internet: http://www.goenergi.dk/publikationer/handlingsplaner/handlingsplan-2011, [accessed 1/7/2011] 
Goenergi.dk 2011b, Om Boligtjek. Obtained through the Internet: https://www.goenergi.dk/forbruger/boligtjek/om-boligtjek, [accessed $1 / 7 / 2011]$

Govan, Greason \& McAllistor (1983) Thermal Insulation, Materials, and Systems for Energy Conservation in the ' 80 s, Baltimore

Gram, JE 2008, Parcelhusets om-og tilbygninger en vejledning. Obtained through the Internet: http://www.bolius.dk/fileadmin/bolius.dk/ pdf-shop/kapitel1-Parcelhusets-om-og-tilbygning.pdf [accessed 21/5/2012]

Grønhøj, A \& Thøgersen, J 2010, Testhusholdningers Erfaringer med et Feedbacksystem for elforbrug på apparatniveau designet på basis af brugerdrevet innovation - en kvalitativ undersøgelse. Handelshøjskolen, Århus Universitet, Institut for Marketing og Statistik

Helm, D og Hepburn, C eds. 2009, The Economics and Politic of Climate Change, Oxford: Oxford University Press

Hoff, J ed. 2004, Danmark som Informationssamfund, Aarhus: Aarhus Universitetsforlag

Jyllandsposten 2009, Gronne afgifter stiger op mod 1500 kroner. Obtained through the Internet: http://jp.dk/indland/indland_politik/ article1619431.ece, [accessed 15/7/2011]

Kant, I 1785, (re-published 2008), Fundamental Principles of the Metaphysic of Morals, Forgotten Books.

Kachadorian, J 1997, The Passive Solar House, Chelsea Green Publishing Company, Vermont

Kanstrup, AM \& Christiansen, E 2009, User-driven Points for Feedback Motivated Electricity savings in Private Households, Joint Actions on Climate Change.
Klima og Energiministeriet 2011, Sektorer og virkemidler. Obtained through the Internet: http://www.kemin.dk/da-DK/KlimaogEnergipolitik/danmark/reduktionafdrivhusgasser/sektorerogvirkemidler/Sider/Forside.aspx [accessed 15/7/2011]

Laclau, E \& Mouffe, C 1985, Hegemoni and Socialist Strategy - Towards a Radical Democratic Politics, Norfolk: Verso

Lamptech 2012, Philips Tornado Asian Compact Fluorescent, Obtained through the Internet:http://www.lamptech.co.uk/Spec\%20Sheets/ Philips\%20CFL\%20Tornado.htm [accessed 21/05/2012]

March, JG \& Olsen, JP 1989, Rediscovering Institutions. The Organizational Basis of Politics, New York: Free Press.

Nedergaard, P og Fristrup, P eds. 2009, Klimapolitik - dansk, europeisk, globalt, København: Jurist- og Økonomforbundets Forlag.

ScienceDaily 2009a, Fossil fuel carbon dioxide emissions up by 29 percent since 2000. Obtained through the Internet: http://www.sciencedaily. com/releases/2009/11/091117133504.htm [accessed 15/7/2011]

ScienceDaily 2009b, Carbon Emissions Linked To Global Warming In Simple Linear Relationship. Obtained through the Internet: http:// www.sciencedaily.com/releases/2009/06/090610154453.htm [accessed 15/7/2011]

WasteOnline 2004, History of waste and recycling sheet. Obtained through the Internet: http://dl.dropbox.com/u/21130258/resources/ InformationSheets/Historyof Waste.htm [accessed 15/7/2011]

Wrap 2006, UK Plastics Waste - A review of supplies for recycling, global market demand, future trends and associated risks. Obtained through the Internet: http://www.wrap.org.uk/downloads/UK_Plastics_Waste.d5a7bbfa.5543.pdf [accessed 15/7/2011] 